\title{
Aplicación de técnicas de cultivo in vitro en la propagación del aliso con vistas a su conservación
}

Recibido: 7 xullo 2011 / Aceptado: 14 outubro 2011

(C) IBADER- Universidade de Santiago de Compostela 2011
Resumen Se ha desarrollado un protocolo eficaz para el establecimiento in vitro mediante la proliferación de yemas axilares de material procedente de genotipos adultos de aliso. Las estaquillas, obtenidas de árboles de 20-30 años, fueron "forzadas" a brotar y los brotes se cultivaron en medio Woody Plant Medium (WPM) (Lloyd y McCown, 1980) con $2 \mathrm{mg} / \mathrm{l}$ de benciladenina (BA) y $0,5 \mathrm{mg} / \mathrm{l}$ de ácido indol-3-acético (AIA). El mantenimiento de los cultivos se realiza mediante subcultivos secuenciales cada 9 semanas en el mismo medio mineral adicionado con $0,1 \mathrm{mg} / \mathrm{l}$ de $\mathrm{BA}$ y $0,5 \mathrm{mg} / \mathrm{l}$ de AIA. Transferencias a medio fresco cada 3 semanas, la inclusión de la zeatina $(Z)$ en el último ciclo y la sustitución de sacarosa $3 \%$ por glucosa $2 \%$, mejoran las tasas de multiplicación y la calidad de los brotes. Los brotes obtenidos en la etapa de multiplicación fueron enraizados con facilidad incluso en el tratamiento sin auxina (84,0\%), aunque la presencia de ácido indol-3-butírico (AIB) en el medio incrementó los porcentajes de enraizamiento, especialmente cuando la glucosa $2 \%(93,4 \%)$ fue incorporada al medio en vez de sacarosa $3 \%(86,9 \%)$. Las plantas enraizadas fueron aclimatadas en una cámara de crecimiento durante 6 semanas, y posteriormente transferidas al invernadero.

Palabras clave Alnus glutinosa $\times$ aliso común $\times$ conservación de germoplasma $\times$ micropropagación $\times$ Phytophthora alni

Elena Corredoira · María C. San José

Departamento de Fisiología Vegetal, Instituto de Investigaciones Agrobiológicas de Galicia, CSIC, Avda de Vigo s/n., Apartado 122, 15080 Santiago de Compostela, España.

Tel:981590958, Fax : 981592504

E-mail: elenac@iiag.csic.es

Laura V. Janeiro

INLUDES. Diputación Provincial de Lugo, Ronda da Muralla 140, 27004 Lugo, España.
Summary An efficient protocol was developed for the in vitro establishment of axillary buds from material obtained from mature alder specimens of different genotypes. The cuttings, obtained from 20 to 30 year-old-trees, were forced flushed and the shoots were cultured in Woody Plant Medium (WPM) (Lloyd and McCown, 1980) with $2 \mathrm{mg} / \mathrm{l}$ benzyladenine (BA) and $0.5 \mathrm{mg} / \mathrm{l}$ indol-3-acetic acid (IAA). The cultures were maintained by sequential subculture every 9 weeks on the same mineral medium, but with 0.1 $\mathrm{mg} / \mathrm{l} \mathrm{BA}$ and $0.5 \mathrm{mg} / \mathrm{l} \mathrm{IAA}$. Transfer to fresh medium every 3 weeks, the inclusion of zeatin $(Z)$ in the final cycle and substitution of $3 \%$ sucrose with $2 \%$ glucose improved the rates of multiplication and the quality of the shoots. The shoots obtained at the multiplication stage rooted easily, even without auxin (84.0\%), although the presence of indol3-butiric acid (IBA) in the medium increased the rooting success, especially when glucose $2 \%$ was used $(93.4 \%)$ in place of sucrose $3 \%(86.9 \%)$. The rooted plants were acclimatized in a growth chamber for 6 weeks before being transferred to the greenhouse.

Key words Alnus glutinosa $\times$ black alder $\times$ germplasm conservation $\times$ micropropagation $\times$ Phytophthora alni

\section{Introducción}

El género Alnus se distribuye por toda Europa, Asia y noroeste de África. En Europa están presentes cuatro especies, el aliso común (Alnus glutinosa), el aliso gris $(A$. incana), el aliso italiano ( $A$. cordata) y el aliso verde $(A$. viridis). De ellas, Alnus glutinosa (L) Gaertn es la más frecuente en España, presente en toda la Península, excepto en las provincias más secas. Vive en márgenes de ríos, arroyos y cursos de agua en general, desde el nivel del mar hasta lo alto de las montañas (0-1700 m). En Galicia, se encuentra en las cuatro provincias, en bosques de ribera, vaguadas y humedales, donde forma alineaciones o pequeños bosquetes, a menudo mezclado con otras frondosas (Álvarez et al. 2000). En general, los alisos son especies pioneras, capaces de colonizar el suelo desnudo y con gran capacidad de tolerar los sitios húmedos. Las 
raíces de estos árboles se caracterizan por poseer nódulos especializados que fijan el nitrógeno atmosférico como resultado de una asociación simbiótica con el actinomiceto Frankia alni. Esta asociación resulta muy beneficiosa, pues el nitrógeno que fijan está disponible tanto para el árbol de acogida como para el medio donde crece. El aliso común, en particular, posee además un valor paisajístico considerable a lo largo de los cursos de agua, jugando un papel vital en los ecosistemas ribereños dado que su sistema radicular ayuda a estabilizar las riberas de los ríos (Gibbs et al. 1999).

En los últimos años las poblaciones de aliso se han visto seriamente afectadas por una enfermedad ocasionada por el hongo Phytophthora alni (Brasier et al. 2004), y que ha recibido el nombre de pudrición de la raíz y del collar de los alisos. Los síntomas de la misma son el amarilleamiento de las hojas, la muerte regresiva de las ramas, el aumento de la producción de frutos y la necrosis de la corteza en el cuello y la parte inferior del tallo (Gibbs et al. 1999). La enfermedad, que se observó por primera vez en el Reino Unido a inicios de los años noventa, se ha dispersado a otras partes de Europa, principalmente Europa Central con gran rapidez (Gibbs et al. 1999; Gibbs et al. 2003). En España, aunque los primeros signos de mortalidad en las alisedas del norte de la Península se observaron en 2006 (Tuset et al. 2006), la presencia del hongo se ha confirmado recientemente (Pintos et al. 2010; Solla et al. 2010). En la actualidad se sabe que está extendida a lo largo de toda la cornisa cantábrica, desde Navarra hasta el golfo Ártabro, así como en la cornisa atlántica gallega y en áreas limítrofes castellano-leonesas y portuguesas.

El reconocimiento de la importancia de estas especies para la estabilidad de los ecosistemas riparios, y el peligro que representa la extensión de la enfermedad, hacen necesario desarrollar estrategias para la conservación de las poblaciones más importantes. Aunque está reconocido que el mecanismo más efectivo para la conservación de una especie es su conservación in situ (Iriondo 2001), en el caso del aliso dado que no existen de momento mecanismos eficaces para el control de la enfermedad (Webber et al. 2004; Jung \& Blaschke 2004), la conservación en su hábitat natural no parece factible. Dentro de los métodos de conservación ex situ los bancos de semillas constituyen uno de los sistemas más empleados y eficientes (Piovan et al. 2010), sin embargo en los últimos años están adquiriendo cada vez más importancia las técnicas de cultivo in vitro, porque además de constituir una forma de propagación clonal son un método complementario a las técnicas de conservación tradicionales (Piovan et al. 2011). De tal forma que la combinación de las técnicas de micropropagación con las de crioconservación o almacenamiento de material biológico en nitrógeno líquido permite la conservación del germoplasma vegetal durante largos períodos de tiempo (Rajora \& Mosseler 2001). De las tres vías de la micropropagación, la proliferación de yemas axilares es el método más utilizado en la actualidad, puesto que garantiza la estabilidad genética y es de fácil aplicación a una amplia variedad de especies (Toribio \& Celestino 2008; Ahmad \& Anis 2011). En el aliso se han desarrollado numerosos protocolos para la micropropagación mediante la proliferación de yemas axilares en muchas especies del género (Garton et al. 1981; Périnet \& Lalonde 1983; Tremblay \& Lalonde 1984; Tremblay et al. 1986; Périnet \& Tremblay 1987; Barghchi 1988; Welander et al. 1989), pero en todos estos trabajos el material de partida son semillas o plántulas, y por tanto de valor genético desconocido. A pesar de los avances descritos en los últimos años en la micropropagación de especies leñosas (Merkle et al. 2007; Pijut et al. 2007; Pijut et al. 2011), en el aliso existen muy pocos artículos que utilicen material adulto en su propagación (Lall et al. 2005; San José et al. 2010). Dado que es difícil predecir las características de un árbol cuando éste aún está en fase juvenil, y además muchos de los especímenes de aliso a conservar están en estado adulto, es necesario desarrollar protocolos para la propagación de esta especie a partir de este tipo de material.

El objetivo de este trabajo es la revisión de los principales resultados obtenidos, en los últimos años, por nuestro grupo, en el establecimiento in vitro de material procedente de árboles de aliso, que se encuentran en formaciones aluviales situadas en las Insuas do Miño, zonas de gran valor ambiental, que forman parte de la Reserva de la Biosfera "Terras do Miño". Estos protocolos nos permitirán desarrollar posteriormente métodos de conservación, como el almacenamiento en nitrógeno líquido, que permitan la preservación de esta especie que se encuentra severamente amenazada por el avance del hongo Phytophthora alni.

\section{Material y métodos}

\section{Establecimiento de los cultivos}

Para el establecimiento in vitro de los cultivos de aliso se recogieron ramas de la copa de 4 árboles sanos, de entre 25-30 años, situados en la zona de Rabadé perteneciente a la Reserva de la Biosfera "Terras do Miño" (clones R1, R2, R3 y R4), situada en la provincia de Lugo, y renuevos basales de un árbol de entre 20-25 años, sin síntomas de enfermedad, localizado en las proximidades de Santiago de Compostela (clon G1). Para todos los clones se realizó la recogida de material en el mes de junio y para los clones R1, R3 y R4 también en noviembre. Segmentos de 20-25 $\mathrm{cm}$ (estaquillas) de cada genotipo se situaron en posición vertical en bandejas con perlita humedecida y se forzaron a brotar en una cámara de crecimiento con una temperatura de $25^{\circ} \mathrm{C}$, una humedad relativa de $80-90 \%$, un fotoperíodo de $16 \mathrm{~h}$ y una intensidad lumínica de $90-100 \mu \mathrm{mol} \mathrm{m}^{-2} \mathrm{~s}^{-1}$. Después de 2-3 semanas se observó el desarrollo de brotes en la estaquillas que sirvieron para obtener los explantos iniciales para el establecimiento de los cultivos in vitro (Fig. 1). Esos brotes, con una longitud de $2-4 \mathrm{~cm}$, y desprovistos de hojas, fueron esterilizados mediante inmersión en alcohol de $70^{\circ}$ durante 20 segundos, seguido de una solución al $0,6 \%$ de cloro libre (Tabletas Millipore ${ }^{\circledR}$ ) con 1 $\mathrm{mg} / \mathrm{l}$ de Tween 80 , durante 8 minutos, seguido de 3 aclarados con agua destilada estéril. Una vez esterilizados, segmentos apicales y nodales $(5-8 \mathrm{~mm})$, obtenidos a partir 
de los brotes esterilizados, se situaron en posición vertical en tubos de vidrio de 20x150 mm, con tapones Kap-uts (Bellco ${ }^{\circledR}$ ) que contenían $16,5 \mathrm{ml}$ de medio de establecimiento que consistió en medio mineral WPM suplementado con sacarosa 3\%, agar Difco 0,7\%, $2 \mathrm{mg} / \mathrm{l} \mathrm{de}$
BA y $0,5 \mathrm{mg} / \mathrm{l}$ de AIA (Tabla 1 ). Después de 3 semanas del inicio del cultivo se determinó el porcentaje de explantos que mostraban contaminación tanto fúngica como bacteriana y el porcentaje de estaquillas que habían sido capaces de desarrollar brotes (capacidad de brotación).

\begin{tabular}{|c|c|c|c|}
\hline & Establecimiento & Multiplicación & Enraizamiento \\
\hline Medio basal & WPM & WPM & $1 / 2$ WPM \\
\hline AIA $\mathrm{mg} \mathrm{I}^{-1}$ & 0,5 & 0,5 & -- \\
\hline BA $\mathrm{mg} \mathrm{I}^{-1}$ & 2 & $0,1-0,2$ & -- \\
\hline Zeatina $\mathrm{mg} \mathrm{r}^{-1}$ & -- & 0,5 & -- \\
\hline AIB $\mathrm{mg} \mathrm{r}^{1}$ & -- & -- & 0,1 \\
\hline Sacarosa $\mathrm{g} \mathrm{l}^{-1}$ & 30 & -- & -- \\
\hline Glucosa $\mathrm{g} \mathrm{r}^{-1}$ & -- & 20 & 20 \\
\hline Agar Bacto Difco $\mathrm{g} \mathrm{r}^{1}$ & 7 & 7 & 7 \\
\hline $\mathrm{pH}$ & 5,7 & 5,7 & 5,7 \\
\hline
\end{tabular}

Woody Plant Medium (WPM) (Lloyd y McCown, 1980) $1 \frac{1}{2}$ WPM medio mineral WPM con los macronutrientes reducidos a la mitad; BA benciladenina; AIA ácido indoł3-acético; AIB ácido indol-3-butírico.
Tabla 1.- Medios de cultivo utilizados en las etapas de establecimiento, multiplicación y enraizamiento durante la micropropagación del aliso común mediante la proliferación mediante yemas axilares

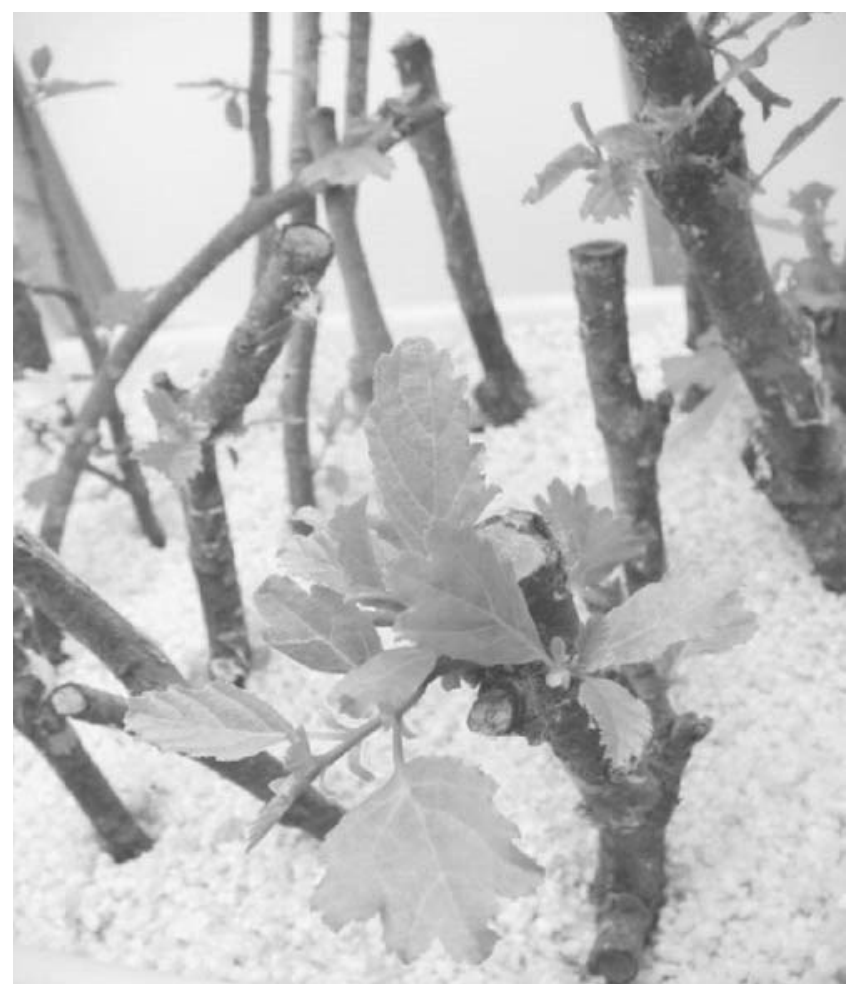

Figura 1.- Estaquillas de aliso con desarrollo de brotes después de 2-3 semanas en una cámara de crecimiento. Estos brotes, posteriormente, fueron utilizados como explantos en el establecimiento de material in vitro de aliso

\section{Mantenimiento y multiplicación de los cultivos}

El cultivo de los brotes de aliso se realiza en posición vertical, en tubos de vidrio de $30 \times 150 \mathrm{~mm}$, con tampones de aluminio, con $20 \mathrm{ml}$ de medio en cada uno. En esta etapa se ha utilizado también como medio mineral, el medio WPM al que se incorporó una fuente hidrocarbonada (sacarosa (3\% ó $2 \%$ ) o glucosa ( $3 \%$ ó $2 \%)$ ) y se solidificó con agar Difco $0,7 \%$ (Tabla 1). Como reguladores del crecimiento se han utilizado $0,5 \mathrm{mg} / \mathrm{l}$ AIA con diferentes combinaciones de BA y $Z$, tal y como se describe en el apartado de Resultados y discusión. En los diferentes experimentos realizados se evaluaron los siguientes parámetros: número total de brotes, número de brotes de entre $0,5-1 \mathrm{~cm}$, número de brotes mayores de un $1 \mathrm{~cm}$, y longitud del brote más largo $(\mathrm{mm})$. Los datos se recogieron al final de los 3 ciclos de multiplicación (9 semanas) y se utilizaron 18 explantos por experimento, repitiéndose todos los experimentos 3 veces.

\section{Enraizamiento}

Para el enraizamiento, se utilizaron brotes de $15-20 \mathrm{~cm}$ aislados de cultivos al final de la etapa de multiplicación (9 semanas) que se transfirieron a tubos de vidrio de 20x150 $\mathrm{mm}$, con tapones Kap-uts (Bellco ${ }^{\circledR}$ ) que contenían 16,5 ml de enraizamiento (Tabla 1). En esta etapa, se evaluó el efecto de la ausencia/presencia de auxina $(0,1 \mathrm{mg} / \mathrm{I}$ AIB) en el medio y del tipo de fuente hidrocarbonada (sacarosa $3 \%$ o glucosa $2 \%$ ). Los brotes se mantuvieron durante los 7 días en el medio de enraizamiento con y sin auxina, y luego los brotes tratados con auxina fueron transferidos a un medio desprovisto de ella. La concentración de auxina empleada en este trabajo se seleccionó teniendo en cuenta la experiencia previa de nuestro grupo en otras especies leñosas (Corredoira et al. 2008). Después de 4 semanas, se procedió a evaluar los siguientes parámetros: porcentaje de brotes que habían enraizado, número de raíces por brote enraizado y longitud de la raíz más larga por brote enraizado ( $\mathrm{mm})$.

En la Tabla 1, se presenta un resumen de los medios de cultivo que han sido definidos para las etapas de establecimiento, multiplicación y enraizamiento. En todas 
las etapas, los medios de cultivo, una vez ajustado el $\mathrm{pH}$ $(5,7)$, se esterilizaron en autoclave a una presión de 1,05 atmósferas durante 20 minutos, lo que equivale a una temperatura de $115^{\circ} \mathrm{C}$. Asimismo, todos los cultivos se mantuvieron en una cámara de crecimiento con un fotoperíodo de $16 \mathrm{~h}\left(50-60 \mu \mathrm{mol} \mathrm{m} \mathrm{m}^{-2} \mathrm{~s}^{-1}\right)$, y una temperatura de $25 \% 20^{\circ} \mathrm{C}$ (día/noche).

\section{Aclimatación}

Para la aclimatación, las plántulas enraizadas, a las que se les había eliminado los restos de medio de cultivo con agua corriente, se transfirieron a contenedores de poliuretano con
48 orificios $(300 \mathrm{ml})$ que contenían una mezcla de corteza de pino (Pinot ${ }^{\circledR}$, Brión, La Coruña) y perlita $(3: 1 \mathrm{v} / \mathrm{v})$ o sustrato comercial para siembra (Hipercor). La aclimatación se realizó en una cámara de crecimiento con una humedad relativa del $90 \%$, una temperatura $25 \pm 2^{\circ} \mathrm{C}$ y $16 \mathrm{~h}$ de fotoperiodo $\left(90-100 \mu \mathrm{mol} \mathrm{m} \mathrm{m}^{-2} \mathrm{~s}^{-1}\right)$. Las plantas fueron fertilizadas semanalmente con $10 \mathrm{ml}$ de la solución de Hoagland (Hoagland \& Arnon 1941). Se utilizaron 20 plantas por cada tipo de sustrato y el experimento se repitió dos veces. Las tasas de supervivencia se evaluaron a las cuatro semanas de ser transplantadas. Después de seis semanas, las plantas se transfirieron a macetas de un litro y al invernadero donde continuaron su crecimiento.
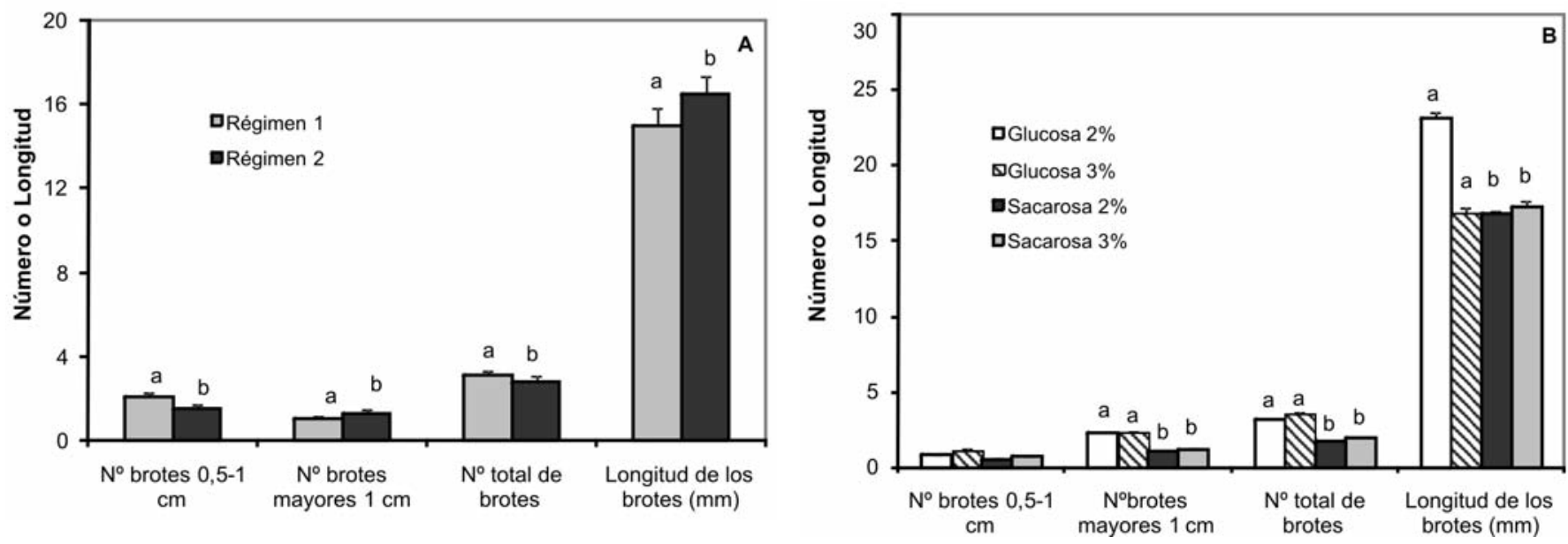

Figura 2.- A. Efecto de la presencia de zeatina en multiplicación de brotes axilares de aliso. B. Efecto del tipo y concentración de la fuente de carbono en la proliferación de brotes axilares de aliso. Columnas (media \pm ES) con la misma letra no difieren significativamente para $p \leq 0,05$

\section{Análisis estadístico}

Los resultados obtenidos en los diferentes experimentos realizados se expresaron como la media \pm error estándar (ES). En la Figura 2A, las diferencias estadísticas entre las medias se calcularon con el test $t$ (MedCalc versión 10.3 software (MedCalc, Marakarke, Belgium)). En la Figura 2B y 3 , los datos fueron analizados mediante un ANOVA II usando SPSS versión 17.0 software para WINDOWS (SPSS Inc., Chicago, USA). Las diferencias estadísticas entre las medias se calcularon con el test de las diferencias mínimas significativas (DMS). Esas diferencias se consideraron significativas a $p \leq 0,05$.

\section{Resultados y discusión}

En un primer experimento se evaluaron diferentes combinaciones de BA (1 y $2 \mathrm{mg} / \mathrm{l}), \quad$ Z $(0,5 \mathrm{mg} / \mathrm{l})$, 2isopentenilaminopurina (2IP) $(2 \mathrm{mg} / \mathrm{l})$, y $\mathrm{AIA}(0,5 \mathrm{mg} / \mathrm{l})$ para el establecimiento in vitro de cultivos del clon G1 (Datos no mostrados). Los resultados obtenidos mostraron que el mejor tratamiento para el establecimiento in vitro de brotes consistía en $2 \mathrm{mg} / \mathrm{l}$ de BA y 0,5 mg/l AIA y, por lo tanto, esta combinación fue la seleccionada para establecer los clones de alisos seleccionados en la Reserva de la Biosfera "Terras do Miño".

La fecha del año en que se toman los explantos está íntimamente relacionada con el estado fisiológico del explanto. Hay periodos específicos en el ciclo de crecimiento anual, en los que los tejidos y los meristemos desarrollan mayor plasticidad morfogénica, lo que condiciona el momento más adecuado para la recolección del material vegetal. Por todo lo mencionado, en un segundo experimento se valoró la influencia de la época de recogida del material vegetal en el establecimiento in vitro de material procedente de genotipos adultos de aliso. Para ello, se recogió material vegetal de los cinco clones durante los meses de junio y noviembre. Los porcentajes de brotación oscilaron entre un 15\% (clon R1) y un $94 \%$ (clon G1) dependiendo del genotipo (Tabla 2). En aquellos clones en los que se efectuaron dos recogidas de material, en junio y noviembre, el material de noviembre presentó los mejores los resultados (clon R1: 15\% de brotación en junio frente a un $66,6 \%$ en noviembre; clon R3: $33,3 \%$ de brotación en 
junio frente a un $77,8 \%$ en noviembre). La influencia de la fecha de recogida de los explantos en el establecimiento in vitro ha sido mencionado para varias especies (Sharma \& Ramamurthy 2000; Takur \& Karnosky 2007). Las tasas de contaminación de los cultivos (principalmente causadas por hongos) también variaron según la época de recogida oscilando entre un $9,1-25 \%$ en junio y un $50-57,1 \%$ en noviembre (Tabla 2).

\begin{tabular}{|c|c|c|c|c|}
\hline \multirow{2}{*}{ Clon } & \multicolumn{2}{|c|}{ Capacidad de brotación (\%) } & \multicolumn{2}{|c|}{ Contaminación (\%) } \\
\hline & Junio & Noviembre & Junio & Noviembre \\
\hline R1 & 15,0 & 66,7 & 9,1 & 56,0 \\
\hline R2 & 44,4 & -- & 25,0 & -- \\
\hline R3 & 33,3 & 77,8 & 10,0 & 57,1 \\
\hline R4 & 43,8 & 60,0 & 23,8 & 50,0 \\
\hline G1 & 94,1 & -- & 15,0 & - \\
\hline
\end{tabular}

Capacidad de brotación: porcentaje de estaquillas que forman brotes después de 3 semanas en la cámara de crecimiento. Contaminación: porcentaje de explantos iniciales que se contaminan después de 3 semanas en cultivo.
Tabla 2.- Efecto de la época de recogida de las estaquillas de aliso común en la capacidad de brotación de las estaquillas y en el porcentaje de contaminación de los explantos iniciales
A pesar de que la brotación de las estaquillas ocurrió en todos los clones evaluados, se observaron considerables diferencias en su comportamiento in vitro, siendo el clon G1 y el clon R4 los obtuvieron un mayor porcentaje explantos reactivos (explantos que reemprenden el crecimiento una vez son establecidos in vitro). Aunque esto puede atribuirse a diferencias genotípicas, también puede deberse a diferencias en la fuente del explanto inicial (clon G1 brotes basales y clon R4 ramas de la copa). Uno de los factores que afectan de manera determinante a la capacidad regenerativa de una planta es la edad de la misma (Bonga \& von Aderkas 1992; Park et al. 2008). De tal manera que el establecimiento in vitro de tejidos vegetales es más fácil cuando más cerca está del estado juvenil el explanto a establecer, pues a medida que se acerca al estado adulto esa capacidad se reduce o incluso se pierde (Rathore et al., 2004). Esta pérdida de la capacidad de morfogénica con la edad de la planta supone un problema, ya que en el caso de los árboles no presentan las características definitivas que los hacen deseables para un uso determinado, hasta que alcanzan el estado adulto (von Aderkas \& Bonga 2000). Una posible solución es utilizar en su micropropagación determinados tejidos como vástagos de raíz, esferoblastos o brotes epicórmicos que retienen ciertas características juveniles, lo que facilita su establecimiento in vitro (Bonga et al. 2010; Vieitez et al. 2011).

Esto está de acuerdo con los resultados obtenidos en este trabajo, de manera que los brotes obtenidos de ramas basales de los árboles adultos (clon G1) fueron más reactivos para el establecimiento in vitro que el material de la copa (clones R1-R4). El uso de la cámara de crecimiento para forzar la brotación de las estaquillas de las ramas de la copa nos ha permitido obtener más explantos vigorosos que los obtenidos directamente del árbol, lo que ha facilitado el establecimiento in vitro de todos los genotipos evaluados. Diversos autores señalan lo ventajoso que es el uso de este tipo de material cuando se quiere micropropagar material maduro, pues además de incrementar el vigor del material a introducir in vitro, reduce la contaminación inicial (Bonga \& von Aderkas 1992; Gomes \& Canhoto 2003; Thakur \& Karnosky 2007; Vieitez et al. 2011).
De los dos tipos de explantos utilizados en el establecimiento, se observó que los explantos apicales eran más reactivos que los explantos basales. Resultados similares han sido mencionados para otras especies leñosas como Eucalyptus nitens (Gomes \& Canhoto 2003) y Arbutus unedo (Gomes \& Canhoto 2009). Estos autores sugieren que la elevada producción de exudados de los explantos basales, o la presencia en los explantos apicales de primordios foliares que producen reguladores de crecimiento, que promueven la división celular y retrasan la senescencia, como posibles explicaciones a ese comportamiento.

Una vez establecido in vitro, el cultivo ha de estabilizarse, es decir, pasar de tener un crecimiento episódico, impredecible y a veces anormal, típico de brotes recién aislados, a tener un crecimiento uniforme y altamente predecible. En general, los cultivos de origen juvenil progresan a esta etapa más rápidamente que los de origen adulto, en los que es necesario un régimen de subcultivos sucesivos durante un periodo de tiempo variable. En nuestro caso la estabilización de los cultivos tuvo lugar entre 5 y 12 meses del inicio del experimento, siendo más corto en el clon $\mathrm{G} 1$ cuyo material de partida, como ya se ha mencionado, también era más juvenil (clon G1 5 meses; clon R1 12 meses; clones R2, R3 y R4 10 meses). Inicialmente los cultivos se mantuvieron en el medio de multiplicación WPM suplementado $0,1-0,2 \mathrm{mg} / \mathrm{l}$ de $B A$ y $0,5 \mathrm{mg} / \mathrm{l}$ de IAA, y subcultivos cada 4-6 semanas. En estas condiciones muchos se fueron perdiendo gradualmente con cada subcultivo y el desarrollo de los brotes que permanecían fue escaso. Esta baja tasa de proliferación aumentó de manera importante cuando se dividió la etapa de multiplicación en 3 ciclos de 3 semanas cada uno, transfiriendo los brotes a medio fresco al final de cada uno de estos ciclos, resultando un período de subcultivo de 9 semanas:

Ciclo 1: BA $0,2 \mathrm{mg} / \mathrm{l}$ más AIA $0,5 \mathrm{mg} / \mathrm{l}$ durante tres semanas

Ciclo 2: BA $0,1 \mathrm{mg} / \mathrm{l}$ más AIA $0,5 \mathrm{mg} / \mathrm{l}$ durante tres semanas 
Ciclo 3: BA $0,1 \mathrm{mg} / \mathrm{l}$ más AIA $0,5 \mathrm{mg} / \mathrm{l}$ durante tres semanas

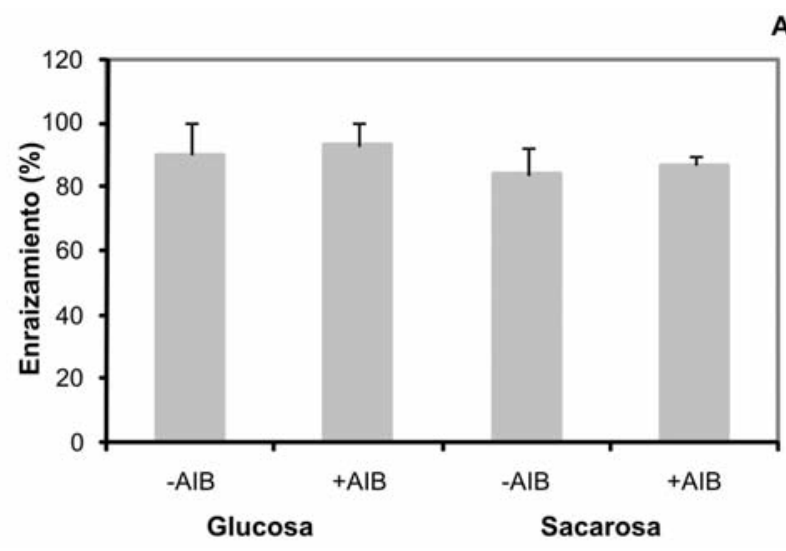

B

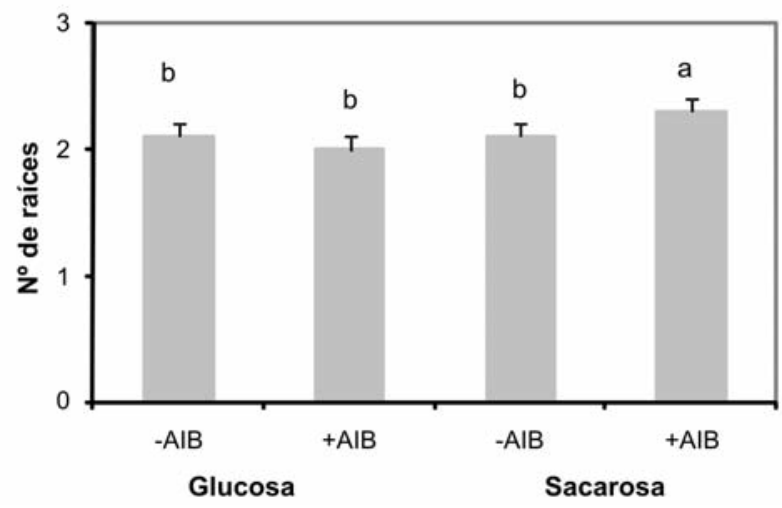

C

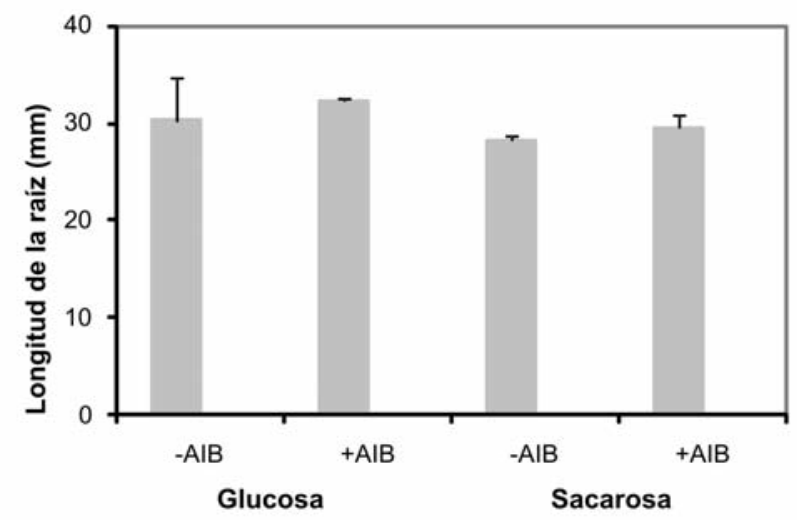

Figura 3.- Efecto del tipo de carbohidrato y de la presencia de AIB en el porcentaje de enraizamiento (A), en el número de raíces (B) y en la longitud de las raíces (C) de brotes axilares de aliso. Columnas (media $\pm E S$ ) con la misma letra no difieren significativamente para $p \leq 0,05$

Esta transferencia a medio fresco cada tres semanas permitió reducir la senescencia apical e incrementar las tasas de proliferación de los cultivos cuando se compararon los cultivos que se mantuvieron en el mismo medio durante 4-6 semanas. De igual manera, las frecuencias de proliferación de brotes axilares de diferentes especies de los géneros Fagus (Vieitez et al. 2003) y Quercus (Vieitez et al. 2009; 2011) aumentaban con transferencias cada dos semanas a medio fresco.

En experimentos previos realizados en nuestro grupo con otras especies leñosas se observó que la combinación de BA con zeatina favorecía la proliferación, pues la adición de zeatina promovía la elongación de los brotes y el desarrollo de las hojas (Vieitez et al. 2009). Por este motivo, se evaluó el efecto de la aplicación de esta citoquinina en dos regímenes diferentes:

Régimen 1: adición de zeatina al medio durante el último ciclo de multiplicación

Régimen 2: adición de zeatina durante los tres ciclos de multiplicación

La presencia de la zeatina en el último ciclo de subcultivo favorece de forma significativa el número total de brotes $(p \geq 0,05)$ (Figura $2 A)$. Sin embargo, la adición de zeatina durante todo el período de multiplicación mejora la elongación de los brotes, aumentando de forma significativa el número de brotes mayores de $1 \mathrm{~cm}(p \geq 0,05)$, lo que se correlaciona con la longitud del brote más largo que también es mayor en este tratamiento (Figura 2A).

No obstante, teniendo en cuenta el número total de brotes y que la adición de zeatina sólo en uno de los ciclos abarata los costes de mantenimiento y multiplicación de los cultivos se decidió elegir el régimen 1. La incorporación de zeatina al medio de cultivo en haya y roble también mejoró la tasa multiplicación y la elongación de los brotes, así como el desarrollo de las hojas (Vieitez et al. 2003; Vieitez et al. 2009). Igualmente, Ishii et al. (2011) mejoran la elongación de brotes axilares de Cryptomeria japonica con la incorporación de zeatina al medio de proliferación. Por tanto, para la multiplicación y mantenimiento de brotes axilares de aliso adulto se propone un periodo de subcultivo de 9 semanas con tres ciclos de transferencias:

Ciclo 1: BA $0,2 \mathrm{mg} / \mathrm{l}$ más AIA $0,5 \mathrm{mg} / \mathrm{l}$ durante tres semanas

Ciclo 2: BA $0,1 \mathrm{mg} / \mathrm{l}$ más AIA $0,5 \mathrm{mg} / \mathrm{l}$ durante tres semanas

Ciclo 3: BA 0,1 mg/l más AIA 0,5 mg/l más Z 0,5 mg/l durante tres semanas

Aunque la sacarosa es el uso común en la gran mayoría de los trabajos en la inducción y multiplicación de brotes en especies leñosas, no siempre es la fuente de carbono más eficaz para estos fines (Thompson \& Thorpe 1987; Kozai 1991; Bonga \& von Aderkas 1992). Algunos azúcares reductores, como la glucosa, han demostrado ser un fuente de carbono más eficiente en la multiplicación de brotes de especies de los géneros Fagus, Malus, Prunus (Cuenca \& Vieitez 2000; Borkowska \& Szczerba 1991; Karhu 1995), en la inducción de yemas adventicias de Fagus (Cuenca \& Vieitez 2000), o en el enraizamiento de Eucaliptus globulus (Corrêa et al. 2005). Por lo tanto, las necesidades de hidratos de carbono deben de ser definidas y optimizadas para cada fase de la micropropagación y en cada especie. En nuestro caso, se ha comprobado que la naturaleza 
química del azúcar añadido al medio de cultivo y su concentración tienen una gran influencia en la proliferación y en el enraizamiento de los brotes axilares de $A$. glutinosa (Figura 2B y 3 ). En la multiplicación, los mejores resultados se obtuvieron al emplear glucosa $2 \%$ o $3 \%$, observándose diferencias significativas ( $\leq \leq 0,001$ para número de brotes mayores de $1 \mathrm{~cm}$ y número total de brotes; $p \leq 0,01$ para longitud del brote más largo) para todos parámetros evaluados a excepción del número de brotes entre 0,5-1 $\mathrm{cm}$. De las dos concentraciones de glucosa ensayadas, la más alta fue la que obtuvo el mayor número de brotes (Figura 2B), si bien con esta concentración aparecen algunos signos de hiperhidricidad, observándose brotes con tallos más gruesos y hojas más engrosadas. La glucosa, al igual que la fructosa, es un azúcar reductor que puede ser absorbido por las superficies de corte, pasando al apoplasto sin gasto de energético, e incorporándose a la glicolisis directamente, mientras que el transporte de la sacarosa al interior de la célula requiere energía y, además una vez dentro ha de ser hidrolizada a glucosa y fructosa con el concurso de la invertasa (Welander et al. 1989). De hecho, cuando se añade sacarosa al medio de cultivo, parte de ella es hidrolizada extracelularmente, y la glucosa procedente de esta hidrólisis es usada preferentemente por el cultivo. Todo esto induce a pensar que es lógico que la glucosa constituya la mejor fuente de carbono para el aliso.

En la etapa de enraizamiento, el tipo de azúcar también influye en el porcentaje de enraizamiento, obteniéndose los mejores resultados en el medio con glucosa y auxina $(93,4 \%$ con glucosa frente $86,9 \%$ sacarosa $3 \%$ ), aunque sin diferencias significativas (Figura $3 \mathrm{~A}$ y $4 \mathrm{~A}$ ). La presencia de glucosa incrementa significativamente la longitud de la raíz más larga ( $p \leq 0,01$; Figura $3 C$ ), sin embargo el número de raíces es superior en los medios suplementados con sacarosa $3 \%$ y auxina, observándose una interacción significativa $(p \leq 0,01)$ entre la presencia de auxina y el tipo de carbohidrato (Figura 3B). Esto está de acuerdo con lo mencionado por Tremblay \& Lalonde (1984), que señalan que el tipo y concentración de carbohidrato añadido al medio de enraizamiento tienen una notable influencia sobre la formación de raíces in vitro en diferentes especies de aliso. Del mismo modo, en Bambusa nutans la presencia de glucosa durante la fase de enraizamiento también mejora la aparición de raíces en brotes establecidos a partir de material maduro (Yasodha et al. 2007). El enraizamiento in vitro es un proceso demandante de energía y al ser la glucosa metabolizada más rápido y más eficazmente que la sacarosa puede inducir una mayor actividad mitótica que conduce a la formación de las raíces (Rolland et al. 2006). Además, se ha determinado que la glucosa puede actuar como una molécula señal en la expresión de genes, en la proliferación celular, en el crecimiento de raíces y inflorescencias, y en la expansión y senescencia de hojas (Gibson, 2004; Cho et al., 2006).

Después de un mes en el medio de enraizamiento, las plantas que habían formado raíces fueron aclimatadas en una cámara de crecimiento. Entre los dos sustratos evaluados (mezcla de corteza de pino (Pinot ${ }^{\circledR}$ ) y perlita (3:1 $\mathrm{v} / \mathrm{v}$ ) o sustrato comercial) no se encontraron diferencias significativas. Las tasas de supervivencia fueron del $91,5 \%$ y $95,0 \%$ respectivamente, después de cuatro semanas en la cámara de crecimiento. A las seis semanas, las plantas que habían sobrevivido se transfirieron a macetas y al invernadero donde continuaron su crecimiento (Figura 4B).
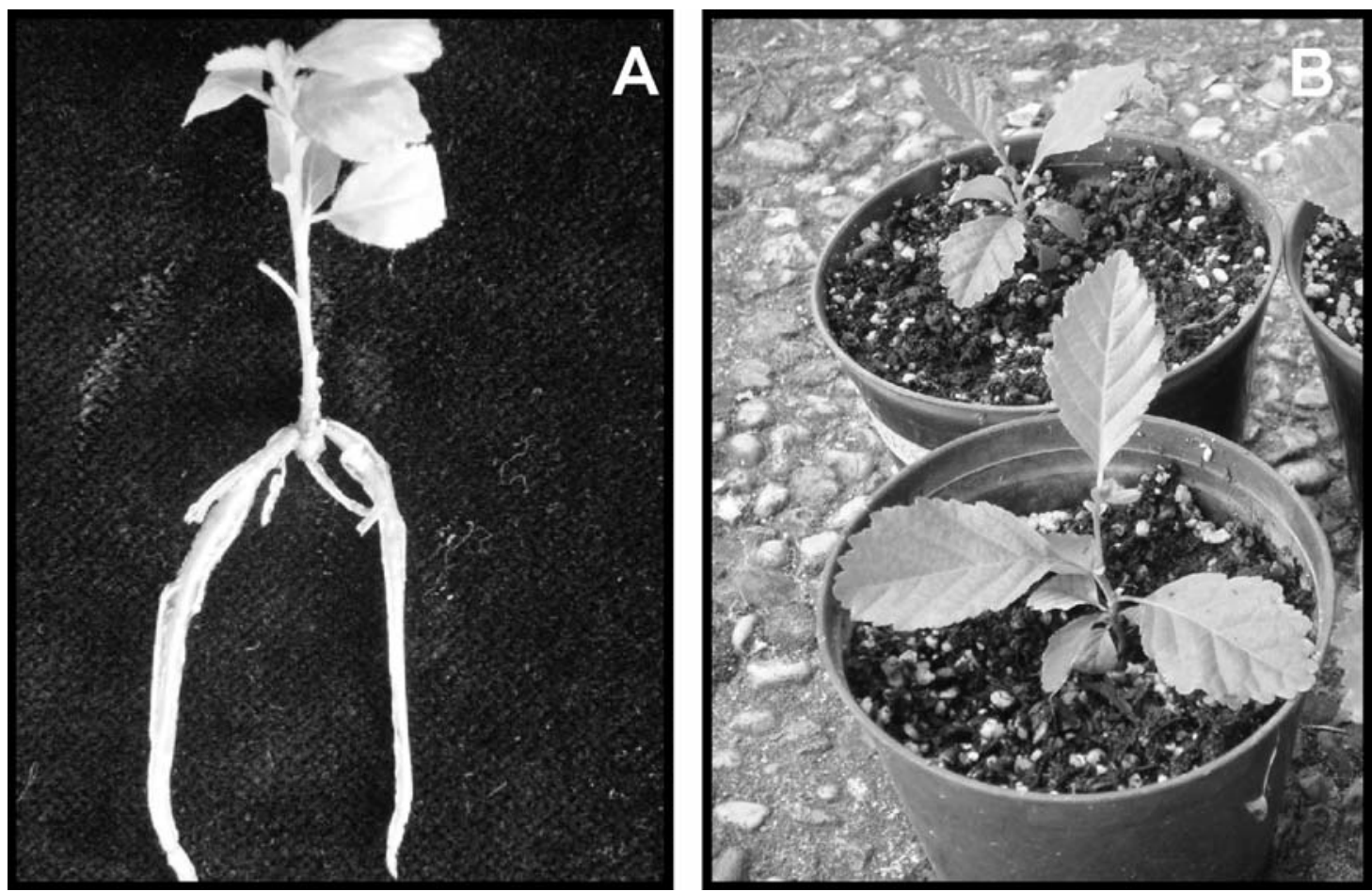

Figura 4.- A. Brote de aliso enraizado después de 4 semanas en medio de enraizamiento suplementado con AIB 0,1 $\mathrm{mg} / \mathrm{l}$ y glucosa $2 \% \mathrm{~B}$. Plantas de aliso a la semana de ser transferidas al invernadero 


\section{Conclusiones}

Las técnicas de cultivo in vitro han contribuido, desde su inicio, de forma muy importante no sólo a la propagación de especies vegetales sino también a su conservación. En este sentido, al determinar las condiciones para la micropropagación mediante la proliferación de yemas axilares del aliso, a partir de material adulto, se ha contribuido a la conservación de los recursos genéticos forestales gallegos, mediante el establecimiento de un banco de germoplasma, que albergará material genético de alisos de la Reserva de la Biosfera Terras do Miño. Una vez establecido un protocolo para la micropropagación del aliso en estado adulto, se están estudiando las condiciones necesarias para su conservación a medio plazo mediante el almacenamiento a bajas temperaturas $\left(4^{\circ} \mathrm{C}\right)$, o largo plazo mediante el almacenamiento en nitrógeno líquido.

Agradecimientos Los autores quieren expresar su agradecimiento a José Carlos Suárez San Martín por su asistencia técnica. Esta investigación ha sido financiada por el Instituto Lucense de Desenvolvemento Económico e Social (INLUDES, Diputación Provincial de Lugo) mediante un Convenio CSIC-INLUDES.

\section{Bibliografía}

Ahmad, N. \& Anis, M. (2011). An efficient in vitro process for recurrent production of cloned plants of Vitex negundo $\mathrm{L}$. Eur. J. Forest Res. 130: 135-144.

Álvarez, P., Barrio, M., Díaz, R.A., Higueras, J., Riesco, G., Rigueiro, A., Rodríguez, R.J. \& Villarino, J.J. (2000). Manual de selvicultura de frondosas caducifolias. Serie Manuales Técnicos. Proyecto Columella, Lugo.

Barghchi, M. (1988). Micropropagation of Alnus cordata (Loisel.) Loisel. Plant Cell Tiss. Organ Cult. 15: 233-244.

Bonga, J.M. \& von Aderkas, J. (1992). In vitro culture of trees. Kluwer Academic Publishers, Dordrecht. 236 p.

Bonga, J.M., Klimaszewska, K.K. \& von Aderkas P. (2010) Recalcitrance in clonal propagation, in particular in conifers. Plant Cell Tiss. Organ. Cult. 100: 241-254.

Borkowska, B., \& Szczerba, J. (1991). Influence of different carbon sources on invertase activity and growth of sour cherry (Prunus cerasus L.) shoot cultures. J. Exp. Bot. 42: 911-915.

Brasier, C.M., Kirk, S.A., Delcan, J., Cooke, D.E.L., Jung, T. \& Man In't Veld, W. A. (2004). Phytophthora alni sp. nov. and its variants: designation of emerging heteroploid hybrid pathogens spreading on Alnus trees. Mycol. Res. 108: 11721184.

Cho, Y.H., Yoo, S.D., \& Sheen, J. (2006). Regulatory functions of nuclear hexokinase 1 complex in glucose signaling. Cell 127: 579-589.

Corrêa, L.R., Paim, D.C., Schwambach, J. \& Fett-Neto, A.G. (2005). Carbohydrates as regulatory factors on the rooting of Eucalyptus saligna Smith and Eucalyptus globulus Labill. Plant Growth Regul. 45: 63-73.
Corredoira, E., Ballester, A. \& Vieitez, A.M. (2008). Thidiazuron-induced high frequency plant regeneration from leaf explants of Paulownia tomentosa mature trees. Plant Cell Tiss. Org. Cult. 95: 98-208.

Cuenca, B. \& Vieitez, A.M. (2000) Influence of carbon source on shoot multiplication and adventitious bud regeneration in in vitro beech cultures. Plant Growth Regul. 32: 1-16.

Garton, S., Hosier, M.A., Read, P.E. \& Farnham, R.S. (1981). In vitro propagation of Alnus glutinosa Gaertn. Hort. Sci. 16: 758-759.

Gibbs, J., Van Dijk, C. \& Webber, J. (2003). Phytophthora disease of alder in Europe. Forestry Commission Bulletin 126. Edinburgh.

Gibbs, J.N., Lipscombe, M.A. \& Peace, A.J. (1999). The impact of Phytophthora disease on riparian populations of common alder (Alnus glutinosa) in southern Britain. Eur. J. Forest Pathol. 29: 39-50.

Gibson, S.I. (2004). Sugar and phytohormone response pathways: navigating a signalling network. J. Exp. Bot. 55: 253-264.

Gomes, A. F. \& Canhoto, J.M. (2003). Micropropagation of Eucalyptus nitens Maiden (Shining gum). In Vitro Cell Dev. Biol.-Plant 39: 316-321.

Gomes, A. F.\& Canhoto, J.M. (2009). Micropropagation of strawberry tree (Arbutus unedo L.) from adult plants. In vitro Cell Dev. Biol.-Plant 45: 72-82

Hoagland, D.R. \& Arnon D.I. (1941). The water culture method for growing plants without soil. Miscellaneous Publications $\mathrm{N}^{\circ}$ 3515. Circular of the California Agricultural Experimental Station 347-361.

Iriondo, J.M. (2001). Conservación de germoplasma de especies raras y amenazadas (Revisión). Invest. Agr.: Prod. Veg. Vol. 16: 5-24.

Ishii, K., Hosoi, Y., Taniguchi,T., Tsubomura, M., Kondo, T.,Yamada, H., Saito, M., Tomohisa Suda, M., Fujisawa, T. \& Tanaka, K. (2011). In vitro culture of various genotypes of male sterile Japanese cedar (Cryptomeria japonica D. Don). Plant Biotechnol. 28:103-106.

Jung, T. \& Blaschke, M. (2004). Phytophthora root and collar rot of alders in Bavaria: distribution, modes of spread, and possible management strategies. Plant Pathol. 53: 197-208.

Karhu, S.T. (1995). The quality of applied carbohydrates affects the axillary branching of apple microshoots. Bull. Rech. Agron. Gembloux 30: 21-27.

Kozai, T. (1991). Micropropagation under photoautotrophic conditions. En: Debergh, P. C., Zimmerman, R. H. (Eds.). Micropropagation-technology and application. Kluwer Academic Publishers, Dordrecht. 447-469.

Lall, S., Mandegaran, Z. \& Roberts, A.V. (2005). Shoot multiplication in cultures of mature Alnus glutinosa. Plant Cell Tiss. Organ Cult. 83: 347-350. 
Lloyd, G. \& McCown, B.H. (1980). Commercially-feasible micropropagation of mountain laurel, Kalmia latifolia, by use of shoot tip culture. Comb. Proc. Int. Plant Propagators Soc. 30: $421-427$

Merkle, S.A., Andrade, G.M., Nairn, C. J., Powell, W.A. \& Maynard, C.A. (2007). Restoration of threatened species; a noble cause for transgenic trees. Tree Genet. Genomes 3: 111-118.

Park, S.Y., Kim, Y.W., Moon, H.K., Murthy, H.N., Choi, Y.H. \& Cho, H.M. (2008) Micropropagation of Salix pseudolasiogyne from nodal explants. Plant Cell Tiss. Organ Cult. 93: 341-346.

Périnet, P. \& Lalonde, M. (1983). In vitro propagation and nodulation of the actinorhizal host plant Alnus glutinosa (L.) Gaertn. Plant Sci. Lett. 29: 9-17.

Périnet, P. \& Tremblay, F.M. (1987). Commercial micropropagation of five Alnus species. New Forest 3: 225230.

Pijut, P.M., Lawson, S.S. \& Michler, C.H. (2011). Biotechnological efforts for presevating and enhancing temperate hardwood tree biodiversity, health, and productivity. In Vitro Cell Dev. Biol.-Plant. 47:123-147.

Pijut, P.M., Woeste, K.E., Vengadesan, G. \& Michler C.H. (2007). Technological advances in temperate hardwood tree improvement including breeding and molecular marker applications. In Vitro Cell Dev. Biol.-Plant. 43: 283-303.

Pintos Varela, C., Rial Martínez, C., Mansilla Vázquez, J.P. \& Aguín Casal, O. (2010). First report of Phytophthora alni subsp. alni in Spain. Plant Dis. 94: 273.

Piovan, A., Caniato, R., Cappelletti, E.M. \& Filippini, R. (2010). Organogenesis from shoot segments and via callus of endagered Kostelezkya pentacarpos (L.) Ledeb. Plant Cell Tiss. Organ Cult. 100: 309-315.

Piovan, A., Cassina, G. \& Filippini, R. (2011). Crambe tataria: actions for ex situ conservation. Biodiver. Conserv. 20: 359371

Rajora, O.P. \& Mosseler, A. (2001). Challenges and opportunities for conservation of forest resources. Euphytica 118: $197-212$.

Rathore, J.S., Rathore, V., Shekhawat, N.S., Singh, R.P., Liler, G., Mahendra, P. \& Dagla, H.R. (2004). Micropropagation of Woody Plants. En: Srivastava, P.S, Narula, A., Srivastava, S. (Eds.) Plant Biotechnology and Molecular Markers, Anamaya Publishers, New Dehli. 195205.

Rolland, F., Gonzalez, E.B., \& Sheen, J. (2006). Sugar sensing and signaling in plants: conserved and novel mechanisms. Annu. Rev. Plant Biol. 57: 675-709.

San José, M.C., Janeiro, L.V., \& Corredoira, E. (2010). Micropropagación del aliso común para la conservación de su germoplasma. Spanish J. Rural Develop. 3:31-38.

Sharma, S.K. \& Ramamurthy, V. (2000). Micropropagation of 4-year-old elite Eucalyptus tereticornis tree. Plant Cell Rep. 19: $511-518$
Solla, A., Pérez-Sierra, A., Corcobado, T., Haque, M.M., Diez, J.J. \& Jung, T. (2010). Phytophthora alni on Alnus glutinosa reported for the first time in Spain. Plant Pathol. 59:789.

Thakur, R.C. \& Karnosky, D.F. (2007) Micropropagation and germoplasma conservation of Central Park Splendor Chinese elm (Ulmus parvifolia Jacq. "A/Ross Central Park") tress. Plant Cell Rep. 26: 1171-1177.

Thompson, M. \& Thorpe, T. (1987). Metabolic and nonmetabolic roles of carbohydrates. En: Bonga J.M. \& Durzan D.J. (Eds.) Cell and Tissue Culture in Forestry. Martinus Nijhoff Publishers, Dordrecht. 89-112.

Toribio, M. \& Celestion C. (2008). El uso de la biotecnología en la conservación de recursos genéticos forestales. Invest. Agr.: Sist. Recur. For.: Fuera de Serie n. ${ }^{\circ} 2-2000:$ 249-260.

Tremblay, F.M. \& Lalonde, M. (1984). Requirements for the in vitro propagation of seven nitrogen-fixing Alnus species. Plant Cell Tiss. Organ Cult. 3: 189-199.

Tremblay, F.M., Périnet, P. \& Lalonde, M. (1986). Tissue culture of Alnus spp. with regard to symbioses. En: Bajaj Y.P.S. (Ed.). Biotechnology in agriculture and forestry. Trees 1. Springer-Verlag. Berlin, Heidelberg. 87-100.

Tuset J.J., González V., Hinarejos C., Mira J.L. \& Sánchez G. (2006). Prospección para determinar la posible presencia de Phytophthora spp. en las alisedas del norte de España. En: Cobos, J.M. (Ed.). Proceedings of the XXIII Annual Meeting of the Forest Health Working Group, Madrid, Spain, 2006, Comunidad Autónoma de Madrid. 527-37.

Vieitez, A.M., Corredoira, E., Martínez, M.T., San-José, M.C., Sánchez, C., Valladares, S., Vidal, N. \& Ballester A. (2011). Biotechonology of Quercus species. Eur. J. Forest Res. DOI 10.1007/s10342-011-0526-0.

Vieitez, A.M., Corredoira, E., Ballester, A., Muñoz, F., Durán, J. \& Ibarra, M. (2009). In vitro regeneration of the important North American oak species Quercus alba, Quercus bicolor and Quercus rubra. Plant Cell Tiss. Organ Cult. 98: 135-145.

Vieitez, A.M., San José M.C., Sánchez, M.C. \& Ballester, A. (2003). Micropropagation of Fagus spp. En: Jain S.M. et al. (Eds.) Micropropagation of woody trees and fruits. Kluwer Academic Publishers, The Netherlands. 181-215.

von Aderkas, P. \& Bonga, J.M. (2000). Influencing Micropropagation and somatic embryogenesis in mature trees by manipulation of phase change, stress and culture environment. Tree Physiol. 20: 921-928.

Webber, J., Gibbs, J. \& Hendry, S. (2004). Phytophthora Disease of Alder. Forestry Commission Information Note 6. Edinburgh.

Welander, M., Welander, N.T. \& Brackman, A.S. (1989). Regulation of in vitro shoot multiplication in Syringa, Alnus and Malus by different carbon sources. J. Hortic. Sci. 64: 361-366.

Yashodha, R., Kamala, K., Kumar, S.P.A., Kumar, P.D. \& Kalaiarasi, K. (2007). Effect of glucose on in vitro rooting of mature plants of Bambusa nutans. Sci. Hortic. 110: 109-113. 